\title{
Differential promoter methylation may be a key molecular mechanism in regulating BubR1 expression in cancer cells
}

\author{
Hye-Young Park', Yoon-Kyung Jeon ${ }^{2}$, \\ Hyun-Jin Shin ${ }^{1}$, II-Jin Kim ${ }^{3}$, \\ Hio-Chung Kang ${ }^{3}$, Sook-Jung Jeong ${ }^{1}$, \\ Doo-Hyun Chung ${ }^{2}$ and Chang-Woo Lee ${ }^{1,3,4}$ \\ ${ }^{1}$ Department of Molecular Cell Biology \\ Center for Molecular Medicine \\ Samsung Biomedical Research Institute \\ Sungkyunkwan University School of Medicine \\ Suwon 440-746, Korea \\ ${ }^{2}$ Department of Pathology \\ Seoul National University College of Medicine \\ Seoul 110-744, Korea \\ ${ }^{3}$ Research Institute, National Cancer Center \\ Goyang 410-769, Korea \\ ${ }^{4}$ Corresponding author: Tel, 82-31-299-6121; \\ Fax, 82-31-299-6269; E-mail, cwlee@med.skku.ac.kr
}

Accepted 13 February 2007

Abbreviations: 5-Aza-2-DC, deoxycytidine; APC/C, anaphase-promoting complex/cyclosome; ChIP, chromatin immunoprecipitation assay; CIN, chromosome instability

\begin{abstract}
The BubR1 mitotic-checkpoint protein monitors proper attachment of microtubules to kinetochores, and links regulation of chromosome-spindle attachment to mitotic-checkpoint signaling. Thus, disruption of BubR1 activity results in a loss of checkpoint control, chromosomal instability caused by a premature anaphase, and/or the early onset of tumorigenesis. The mechanisms by which deregulation and/or abnormalities of BubR1 expression operate, however, remain to be elucidated. In this study, we demonstrate that levels of BubR1 expression are significantly increased by demethylation. Bisulfite sequencing analysis revealed that the methylation status of two $\mathrm{CpG}$ sites in the essential BubR1 promoter appear to be associated with BubR1 expression levels. Associations of MBD2 and HDAC1 with the BubR1 promoter were significantly relieved by addition of 5-aza-2'-deoxycytidine, an irreversible DNA methyltransferase inhibitor. However, genomic DNA isolated from 31 patients with colorectal carcinomas exhibited a $+84 A / G$ polymorphic change
\end{abstract}

in approximately $60 \%$ of patients, but this polymorphism had no effect on promoter activity. Our findings indicate that differential regulation of BubR1 expression is associated with changes in BubR1 promoter hypermethylation patterns, but not with promoter polymorphisms, thus providing a novel insight into the molecular regulation of BubR1 expression in human cancer cells.

Keywords: Bub1 spindle checkpoint protein; colorectal neoplasms; DNA methylation; polymorphism, genetic

\section{Introduction}

Mitotic-checkpoint controls trigger cell cycle arrest and/or elimination of cells harboring cell cycle defects. Mitotic-checkpoint proteins, such as Bub1, Bub3, BubR1 (a homolog of yeast Bub1 and Mad3), Mad1, and Mad2 preferentially localize to the kinetochores of unaligned chromosomes where they produce a diffusible "wait anaphase" signal (Chen et al., 1996; Taylor and McKeon, 1997; Taylor et al., 1998; Waters et al., 1998; Chan et al., 1999; Abrieu et al., 2000). This signal delays the onset of anaphase by inhibiting the anaphase-promoting complex/cyclosome (APC/C), a multi-subunit E3 ubiquitin ligase required for degradation of securin and the subsequent activation of separase, leading to separation of sister chromatids (Sudakin et al., 1995; Nasmyth et al., 2000; Yu, 2002). Defects in the mitotic-checkpoint function, therefore, result in premature mitosis and mis-segregation of chromosomes, leading to chromosome instability (CIN) and the aneuploidy that is observed in many human cancers (Cahill et al., 1998).

The results of recent studies indicate that human cancer cells contain mutations in the mitotic-checkpoint genes that encode Bub1, BubR1, Mad1, Mad2 and others (Kops et al., 2005). The effect of these mutations on mitotic-checkpoint signaling and/or the oncogenic process, however, has not been examined, with the exception of the mutant Mad1 allele isolated from a lymphoma (Tsukasaki et al., 2001). The first evidence demonstrating mutations in a checkpoint-gene associated with a human disease was reported to involve five families with the rare recessive condition termed mosaic variegated aneuploidy (MVA). A total of nine mutations were found in 
the BUB1B gene that encodes the BubR1 protein (Hanks et al., 2004). It has not been determined whether these mutant alleles affect checkpoint signaling. Nevertheless, it seems that defects in the expression of these checkpoint genes leads to chromosome mis-segregation, causes $\mathrm{CIN}$ and aneuploidy, and facilitates tumorigenesis, particularly in animal models. BubR1 has been shown to inhibit $\mathrm{APC} / \mathrm{C}$ through direct binding to $\mathrm{Cdc} 20$, and thus defects in BubR1-mediated signaling also abolish checkpoint control. BubR1 monitors proper attachment of microtubules to kinetochores and links regulation of chromosome-spindle attachment to mitotic-checkpoint signaling (Taylor et al., 1998; Mao and Abrieu, 2003; Lampson and Kapoor, 2005). Recent observations show that deletion of one BubR1 allele in mice, which express nearly $30 \%$ of normal protein levels, results in enhanced genomic instability and tumor formation (Dai et al., 2004; Wang et al., 2004). Our recent results demonstrate that the apoptotic potential of BubR1 appears to monitor abnormalities in cells that have aberrantly exited from mitotic arrest, and that expression of BubR1 suppresses the development of tumors established with adapted aneuploid cells (Shin et al., 2003).

Additionally, mutant mice with compromised BubR1 expression exhibit aneuploidy, early onset of malignancies, and premature cellular senescence (Baker et al., 2004). These observations indicate that the BubR1 mitotic-checkpoint protein plays an essential role in the maintenance of genomic integrity, and that defects in BubR1-mediated signaling not only eliminate checkpoint control, but are also linked to certain human diseases. Aberrant expression of the BubR1 protein has been frequently observed in human cancer cells (Shin et al., 2003), despite the rarity of genetic alterations of the BUB1B gene in such cells (Saeki et al., 2002). Thus, it is possible that aberrant expression of BubR1 in human cancers is modulated by mechanisms other than mutational inactivation.

In this report we show that differential expressions of BubR1 in human cancers are associated with the status of BubR1 promoter hypermethylation, but not with the status of promoter polymorphisms.

\section{Materials and Methods}

\section{Luciferase assay and immunoblot analysis}

HeLa cells were transfected with the $5 \mu \mathrm{g}$ of promoter construct DNA by electroporation (Bio-Rad) and were harvested using report lysis buffer (Promega) $48 \mathrm{~h}$ later. All transfections were normalized against an internal control ( $\mathrm{pCMV}$ - $\beta$ gal). For immunoblot analysis, cells were harvested by scraping, washed twice in cold PBS, and lysed in a buffer containing $50 \mathrm{mM}$ HEPES (pH 7.2), $250 \mathrm{mM} \mathrm{NaCl}, 2 \mathrm{mM}$ EDTA, $0.1 \% \mathrm{NP}-40,1 \mathrm{mM}$ DTT, $1 \mu \mathrm{g} / \mathrm{ml}$ of aprotinin, $1 \mu \mathrm{g} / \mathrm{ml}$ of leupeptin, and $50 \mu \mathrm{g} / \mathrm{ml}$ of PMSF. Equal amounts of protein from each sample, as determined using the Bio-Rad protein assay, were subjected to SDS-PAGE, transferred to nitrocellulose membranes, and analyzed with anti-BubR1 (BD Biosciences Pharmingen), and anti-Actin (Sigma) antibodies.

\section{Cell lines and subjects}

HeLa, Beas2B, THP-1, and 293 cells were purchased from the ATCC. LL86, L132, Calu-3, HCC95, SK-MES-1, HCC1171, HCC1833, HCC2108, NClH596 and SK-LU-1 cells were purchased from the Korean Cell Line Bank. Surgically resected colorectal carcinoma tissues were obtained from Seoul National University Hospital. All study protocols were approved by the Institutional Review Board of the hospital, and informed consent was obtained as described previously (Chang et al., 2005).

\section{Identification of the promoter sequences and transcription start sites}

A SMART RACE cDNA amplification kit (BD Biosciences Pharmingen) was used to identify the transcription start sites in the BubR1 promoter. First strand cDNA was synthesized from the total RNA of Jurkat $T$ cells, and 5'RACE was performed using universal primer $A$ and a primer specific for BubR1 cDNA (5'-TGTTGTGCAGTCTCTTCCACATATGG-3'). Amplified PCR products were cloned into the pGEM-T-easy (Promega) vector, and 20 clones were then sequenced. To identify the minimal BubR1 promoter region, deletion constructs were progressively generated by PCR and cloned into the pXP2 vector.

\section{PCR and Sodium bisulfite DNA sequencing}

Genomic DNAs were digested with HindIII restriction enzymes and the isolated DNA fragments were denatured with sodium hydroxide $(0.3 \mathrm{~N})$ at $39^{\circ} \mathrm{C}$ for $30 \mathrm{~min}$, then treated with hydroquinone (5.5 $\mathrm{mM})$ and sodium bisulfite $(\mathrm{pH} 5,2.5 \mathrm{M})$. Samples were incubated in a Thermocycler at $55^{\circ} \mathrm{C}$ for a total of $16 \mathrm{~h}$ and punctuated every $3 \mathrm{~h}$ by a $5 \mathrm{~min}$ denaturation at $95^{\circ} \mathrm{C}$. Converted DNAs were desalted using a Wizard DNA clean up kit (Promega), denatured with sodium hydroxide $(0.3 \mathrm{~N})$ at $37^{\circ} \mathrm{C}$ for $15 \mathrm{~min}$, and purified by ethanol precipitation. The bisulfite-modified DNAs were amplified by PCR using BubR1 promoter-specific primers (5'-GTAGTT- 
TGTTTAAGGTTGTATATTTGGTATG-3' and 5'-CCATCCTACATTCCTAACTCAAAT- $\left.3^{\prime}\right)$. Products from nested PCR amplifications (5'-TAAGGGTGGGGTAGGAAATAGTTAGG-3' and 5'-ACTACAAACCTTTAATCTAAACCAC-3') were cloned into the pGEM-T vector (Promega), and 10 clones of each PCR product were sequenced using an M13 reverse primer.

\section{Chromatin immunoprecipitation (ChIP) assay}

ChIP assays were performed according to the manufacturer's instructions (Upstate). Antibodies against MBD2 (Upstate) and HDAC1 (Santa Cruz) were used for immunoprecipitation. Precipitated proteinDNA complexes were washed twice sequentially with a low salt buffer $(20 \mathrm{mM}$ Tris- $\mathrm{HCl}[\mathrm{pH}$ 8.1], 2 $\mathrm{mM}$ EDTA, $150 \mathrm{mM} \mathrm{NaCl}, 0.1 \%$ SDS and $1 \%$ Triton-X100), a high salt buffer $(20 \mathrm{mM}$ Tris- $\mathrm{HCl}[\mathrm{pH}$ 8.1], $2 \mathrm{mM}$ EDTA, $500 \mathrm{mM} \mathrm{NaCl}, 0.1 \%$ SDS and $1 \%$ Triton-X100), an LiCl buffer $(10 \mathrm{mM}$ Tris- $\mathrm{HCl}[\mathrm{pH}$ 8.1], $1 \mathrm{mM}$ EDTA, $250 \mathrm{mM} \mathrm{LiCl,} \mathrm{1 \%} \mathrm{NP40,} 1 \%$ sodium deoxycholate), and $1 \times$ TE buffer. Precipitated proteins and any DNA were dissolved in $1 \times$ TE buffer and incubated at $65^{\circ} \mathrm{C}$ overnight to reverse crosslinks. Following RNase A, proteinase $\mathrm{K}$, phenol/chloroform extraction, and ethanol precipitation, samples were subjected to 40 cycles of PCR amplification. The primers for detection of the BubR1 promoter were 5'-GATAAGCTTGAATTCAAGGGTGGGGCAGGAAAC-3' and 5'-GATTGATCTTCAAGCCCACACCCCTAGCCGCC-3'.

\section{Results}

\section{BubR1 expression is regulated by DNA hypermethylation}

Changes in promoter hypermethylation patterns represent an alternative to genetic lesions as causative factors for the aberrant expression of genes. To examine the possibility that DNA methylation is integral to the regulation of BubR1 expression, Beas2B, HeLa, Jurkat, THP-1, and 293 cells were treated with the irreversible DNA methyltransferase inhibitor 5-aza-2'-deoxycytidine (5-Aza-2-DC), and the BubR1 levels were determined by immunoblotting (Figure $1 \mathrm{~A}$ and $1 \mathrm{~B}$ ). It is of interest that 4 of the 5 cell lines tested (Beas2B, HeLa, Jurkat, and 293), but not actin, contained markedly increased BubR1 protein levels after treatment with 5-Aza-2$\mathrm{DC}$, indicating that BubR1 expression is controlled by promoter hypermethylation. The defined BubR1 gene promoter (GenBank accession no. DQ206625) and its flanking regions contain approximately 34 methylatable CG pairs (Figure 2A). To examine the methylation patterns of these potential substrate sites, DNA isolated from each of the Beas2B and HeLa cell lines was treated with sodium bisulfite, PCR fragments were cloned, and 10 independent clones per cell line were sequenced. We determined that three CG pairs (at $-346,-342$, and -293) among seven methylatable residues in the $5^{\prime}$ region of the minimal BubR1 promoter sequences were highly methylated in both cell lines (Figure 2B). We then assessed whether three of the CG residues were

A

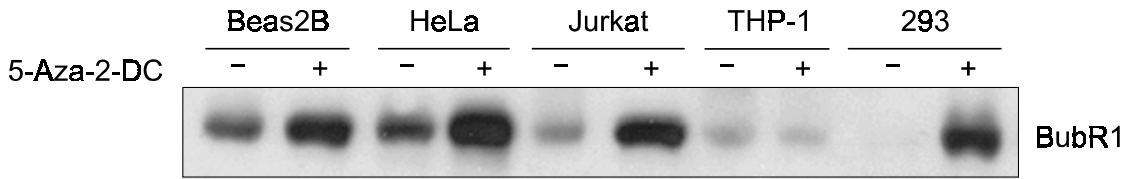

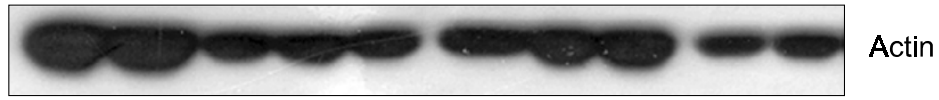

B

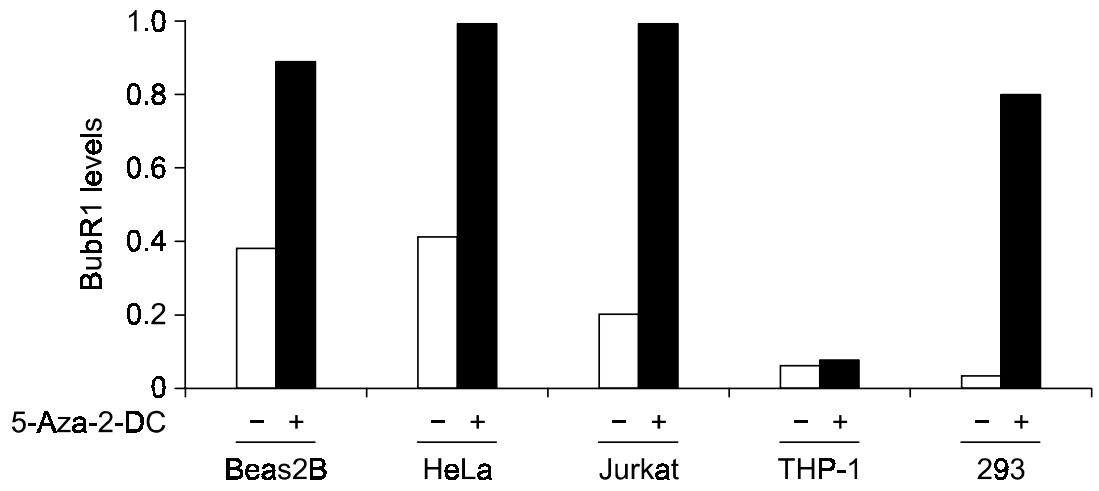

Figure 1. Effect of a demethylating agent on expression of BubR1. (A) Beas2B, HeLa, Jurkat, THP-1 and 293 cells were cultured in the absence (-) or presence $(+)$ of 5-Aza-2-DC (4 $\mu$ mole/l) for $48 \mathrm{~h}$. Protein extracts $(100 \mu \mathrm{g})$ were processed and immunoblotted with anti-BubR1 and anti-Actin antibodies. (B) Gel densities of relative BubR1 levels in each cell line after demethylation were quantified by densitometry. Results are representative of three independent experiments. 


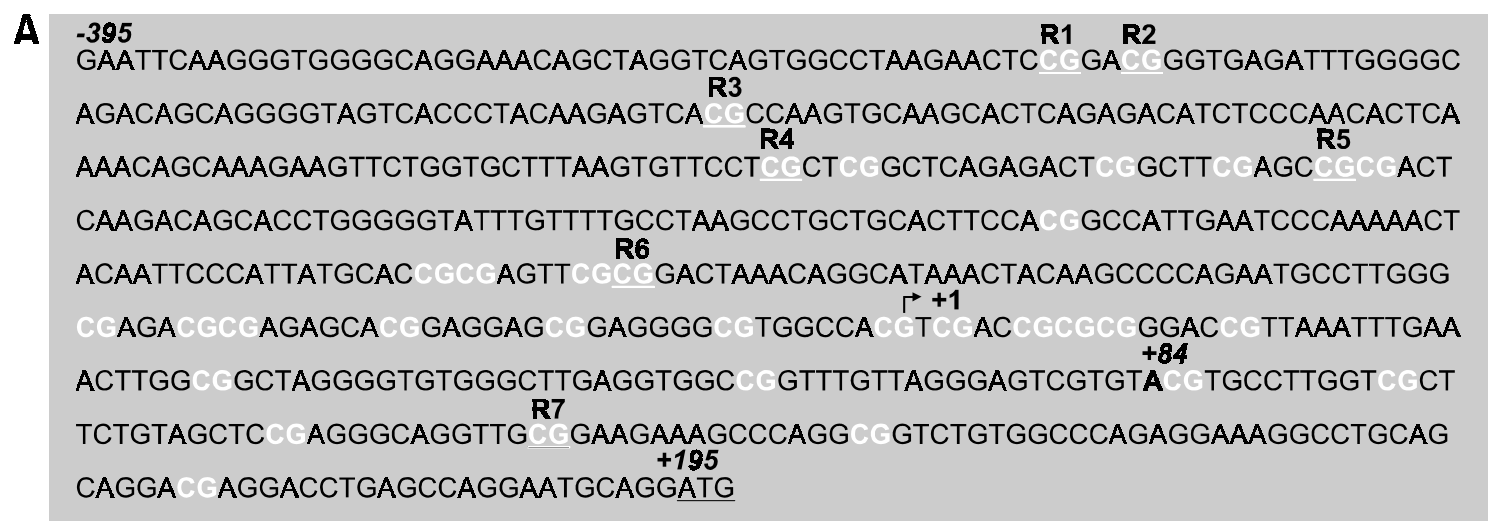

\begin{tabular}{lcc}
\hline & \multicolumn{2}{c}{ Fraction methylated (\%) } \\
\cline { 2 - 3 } & HeLa & Beas2B \\
\hline R1 (-346) & 50 & 70 \\
R2 (-342) & 60 & 60 \\
R3 (-293) & 70 & 50 \\
R4 (-214) & 0 & 10 \\
R5 (-190) & 0 & 10 \\
R6 (-83) & 10 & 0 \\
R7 (+123) & 0 & 10 \\
\hline
\end{tabular}

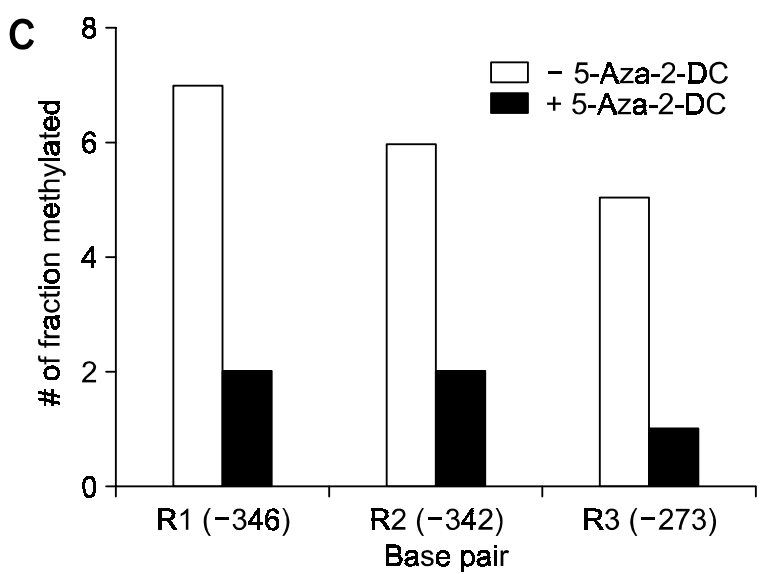

Figure 2. Methylation CG residues in BubR1 promoter. (A) Based on a BLAST homology search and progressive deletion analyses we identified and amplified a 590 nucleotide DNA sequence upstream of the BubR1 coding exon. The BubR1 promoter of parts of this sequence exhibited a nearly 200 -fold higher luciferase activity compared with background activity from the promoterless backbone vector (data not shown). The major transcription start site (arrow) was determined by 5'RACE. CG pairs are marked in white with capital letters. (B) DNAs were isolated from HeLa and Beas2B cells and treated with sodium bisulfite. Amplified PCR fragments (-395 to +195) were cloned into the universal T-vector (pGEM-T) and 10 independent clones were sequenced per PCR fragment using M13 reverse primer. The positions of 7 methylatable CG residues in both cells are presented. (C) HeLa cells were cultured in the absence $(-)$ or presence $(+)$ of 5-Aza-2-DC. DNA was isolated, treated with sodium bisulfite, and used for PCR as described in (B). Ten independent clones were sequenced per PCR fragment. The fractions of methylated CG residues are presented.

demethylated following 5-Aza-2-DC treatment, resulting in enhanced BubR1 protein levels due to demethylation. DNA isolated from Beas2B cells cultured in the absence or presence of 5-Aza-2-DC was treated with sodium bisulfite, cloned, and sequenced. As shown in Figure $2 \mathrm{C}$, these methylated residues were significantly demethylated by 5-Aza-2-DC exposure. These findings indicate that hypermethylation of the BubR1 promoter directly affects BubR1 expression.

The status of promoter hypermethylation is associated with aberrant expression of BubR1 in lung cancer cells

Based on DNA methylation regulation of BubR1 expression, we hypothesized that aberrant expre- ssion of the BubR1 protein in cancer cells is correlated with hypermethylation. To examine this possibility, we monitored the levels of the BubR1 protein in lung cell lines (immortalized nontumor, LL86, and L132; squamous cell carcinoma, Calu-3, HCC95 and SK-MES-1; adenocarcinoma, HCC1171, HCC1833, HCC2108, NCl-H596, and SK-LU-1). We previously examined the expression profiles of the BubR1 protein using human cancer specimens, and our staining results showed that BubR1 is significantly down-regulated in colon (Shin et al., 2003), liver, and lung cancers (data not shown). As shown in Figure 3A, 7 of 10 lung cell lines (LL86, L132, Calu-3, HCC95, SK-MES-1, HCC1171, HCC1833, HCC2108, NCl-H596 and SK-LU-1) exhibited reduced BubR1 protein levels. Therefore, we examined whether the different levels of BubR1 expression 
A

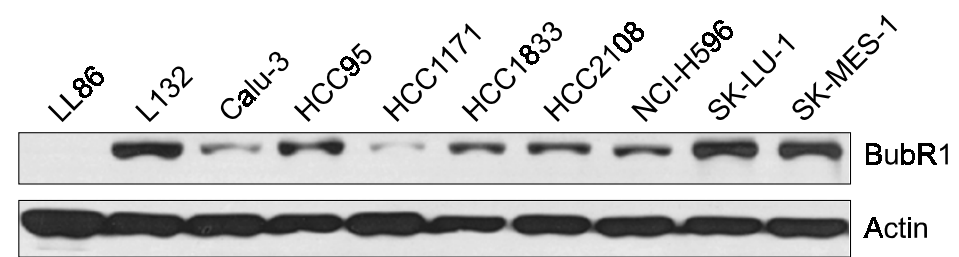

B
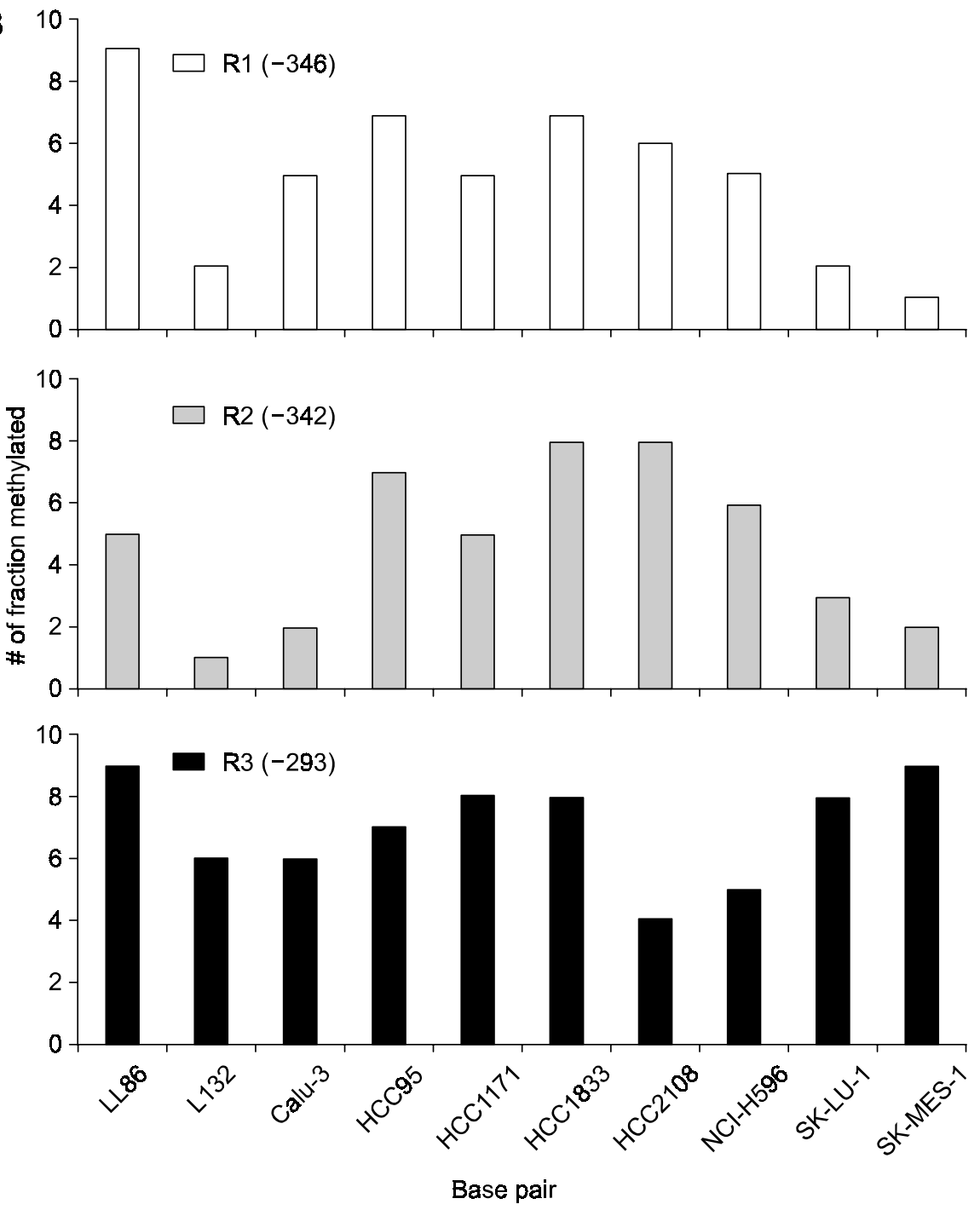

Figure 3. Aberrant expression of BubR1 in lung cancer cells associated with promoter hypermethylation. (A) Ten lung cell lines (immortalized nontumor, LL86 and L132; squamous cell carcinoma, Calu-3, HCC95 and SKMES-1; adenocarcinoma, HCC1171, HCC1833, HCC2108, NCl-H596 and SK-LU-1) were maintained, and protein extracts were immunoblotted with anti-BubR1 and anti-Actin antibodies. (B) DNA was isolated from 10 lung cell lines and treated with sodium bisulfite. Amplified PCR fragments (-395 to $+195)$ were cloned into the universal T-vector (pGEM-T), and 10 independent clones were sequenced per PCR fragment. Fractions methylated at 3 CG residues $-346(\mathrm{R} 1),-342(\mathrm{R} 2)$, and -293 (R3) are shown.

in each lung cell line were associated with the status of promoter hypermethylation. Evaluation of 10 individual clones from each cell line using the bisulfite sequencing analysis method revealed that the methylation status of two $\mathrm{CpG}$ sites at R1 (-346) and R2 (-342) varied depending on the cell line, while the high methylation profile in R3 (-293) was relatively constant throughout (Figure 3B). Three cell lines (L132, SK-LU-1 and SK-MES-1) that showed high levels of BubR1 expression were less methylated at R1 (-346) and R2 (-342). In contrast, cell lines with reduced levels of BubR1 expression (LL86, HCC95, HCC1171, HCC2108, and $\mathrm{NCl}-$ H596), except Calu-3 cells, were densely methylated at these sites. These results indicate that the methylation status of two $\mathrm{CpG}$ sites in the BubR1 promoter appear to be inversely correlated with the expression levels of the BubR1 gene. Apparently, 
differential promoter methylation contributes to silencing or inactivation of BubR1 expression.

\section{Effects of a demethylating agent on the recruitment of DNA methylation-associated factors to the BubR1 promoter}

Recent evidence that methyl-CpG binding proteins (e.g., MBD2 and MeCP2) interact with HDAC1 and HDAC2 and recruit the Sin3 corepressor protein supports a molecular mechanism involving DNA methylation. This mechanism negatively regulates target gene expression either by interfering with transcription factor binding or by facilitating formation of an unfavorable chromatin structure (Bird, 2002). The possibility that silencing or repression of the BubR1 gene is coordinated with the binding of DNA methylation-associated factors, such as MBD2 and HDACs, in the context of promoter methylation status was investigated by ChIP analyses using primers that encompassed the BubR1 gene promoter region (Figure 4). Comparable binding of MBD2 and HDAC1 to the BubR1 promoter was revealed in HeLa cells treated with and without 5-Aza-2-DC. Association of the BubR1 promoter with MBD2 was present prominently in HeLa cells, but was significantly decreased by exposure to 5-Aza-2-DC (compare tracks 3 and 7). Similarly, low levels of association of HDAC1 with the BubR1 promoter were observed in non-treated HeLa cells,

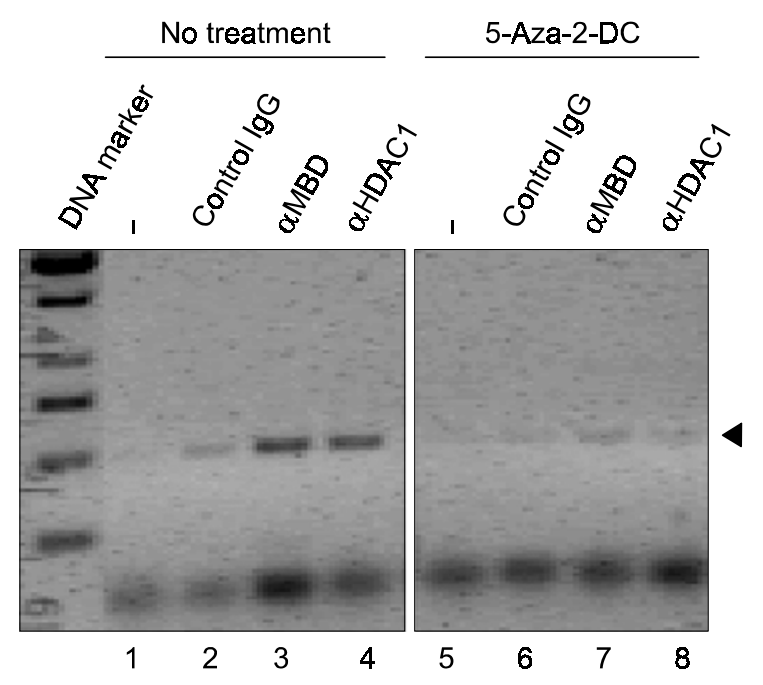

Figure 4. Recruitment of MBD2 and HDAC1 to the BubR1 promoter. ChIP analyses of the association of MBD2 and HDAC1 with the BubR1 promoter region in HeLa cells treated with or without 5-Aza-2-DC. Crosslinked cell lysates were prepared from HeLa cells. Proteins immunoprecipitated with antibodies against MBD2 and HDAC1 or control IgG were decrosslinked. Each DNA extracted from immunoprecipitated chromatin samples was amplified by PCR using BubR1 promoter-specific primers for the region from -395 to +56 . while the association was absent in cells treated with 5-Aza-2-DC (compare tracks 4 and 8). These findings indicate that the methylation states of the BubR1 promoter likely affect the recruitment of DNA methylation-associated factors.

\section{Potential correlation between BubR1 expression and promoter polymorphisms}

To determine whether polymorphic base changes in the BubR1 promoter region affect BubR1 transcription, we sequenced this region in genomic DNA isolated from surgically resected colorectal carcinoma tissues of 31 patients. We found an allelic variation $(+84 \mathrm{~A})$ in the defined BubR1 essential promoter region (Figure $5 A$ and $B$ ). Direct sequencing analysis revealed that the heterozygous $(A / G)$ allele was present in approximately $35 \%$ of the colorectal carcinomas and that the mutant homozygous allele $(\mathrm{G} / \mathrm{G})$ was present in $23 \%$ of these specimens (Figure $5 \mathrm{C}$ ). Therefore, to examine any potential correlation between allelic variation and BubR1 transcriptional activity, we performed luciferase report gene assays using BubR1 promoter constructs $(-395$ to +195$)$ containing either the wild type $(A / A)$ or the mutant homozygous $(G / G)$ alleles. We observed no significant difference in transcriptional activity (Figure 5D), suggesting that this promoter polymorphism is not integrated into the regulation of BubR1 expression.

Our findings provide insight into BubR1 expression and indicate that differential regulation of BubR1 expression is probably associated with DNA hypermethylation, but not with promoter polymorphisms in human cancers.

\section{Discussion}

Recent observations show that MEFs, which are heterozygous for the BubR1 allele, express approximately $30 \%$ of normal protein levels, resulting in defective mitotic arrest and inducing a high frequency of aneuploidy (Wang et al., 2004). It has been reported that mitotic-checkpoint proteins containing cyclin destruction sequences are specifically degraded by the ubiquitin-proteosome machinery, leading to increased formation of aneuploid cells and eventual tumorigenesis. Recently, we also found that during prolonged mitotic arrest, BubR1 becomes degraded in an ubiquitin-dependent manner and that the subsequent inactivation and/or down-regulation of BubR1 prevents induction of the apoptotic cell death that normally occurs following post-mitotic adaptation (Shin et al., 2003). In addition, deletion of one BubR1 allele in a mouse model not only enhanced susceptibility to carcino- 
A

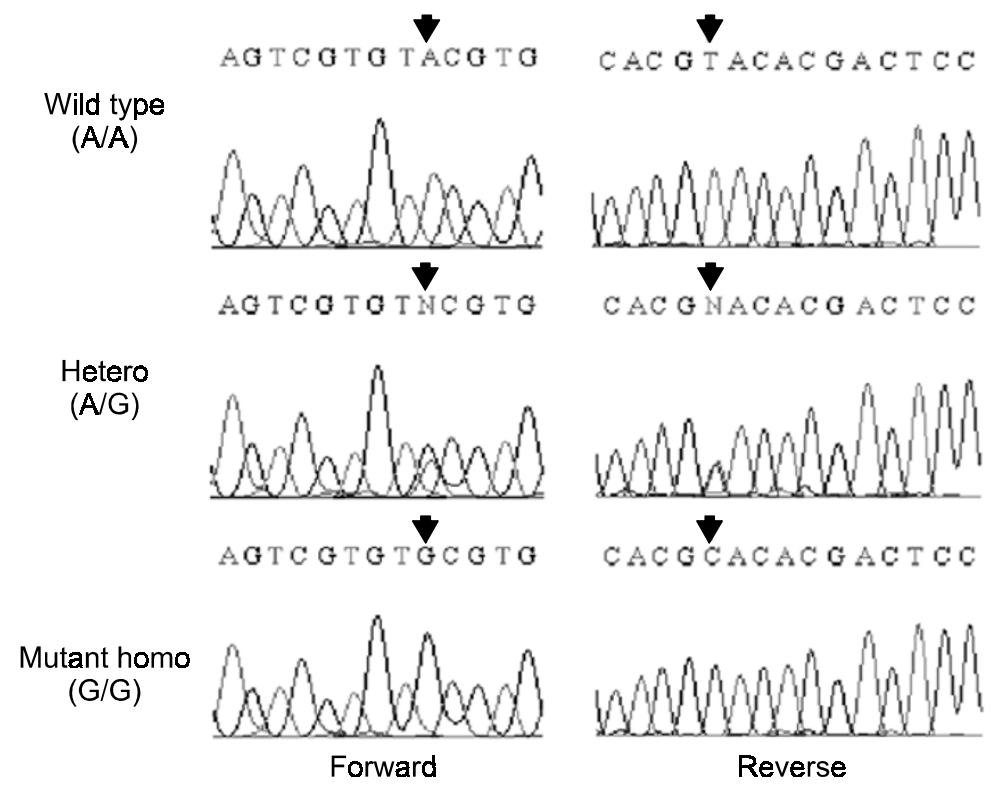

B

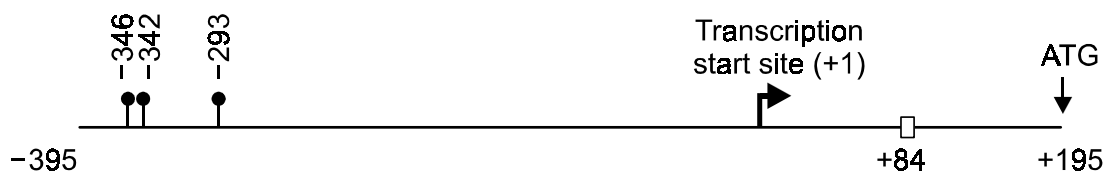

C

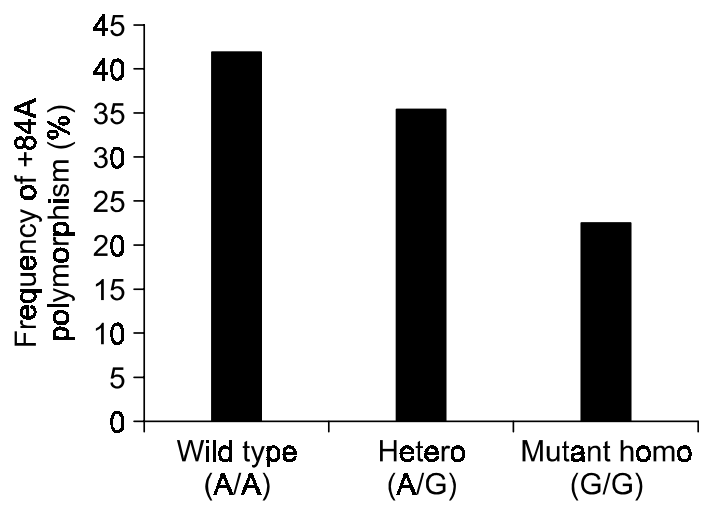

D

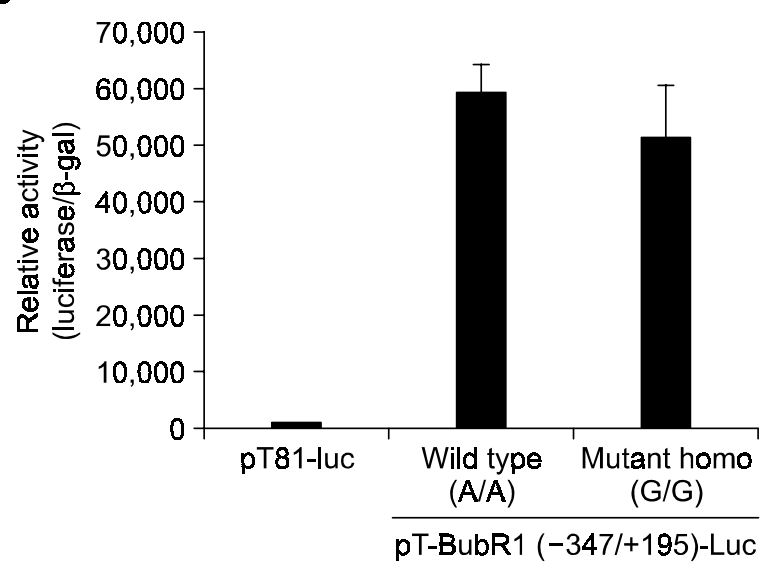

Figure 5. Promoter polymorphism is not involved in regulation of BubR1 transcription. (A) DNA was isolated from surgically resected colorectal adenocarcinoma tissues of 31 patients. The BubR1 promoter region from -395 to +195 was examined by DNA sequencing using forward and reverse primers. Polymorphic changes were observed at $+85 \mathrm{~A}$ in the essential BubR1 promoter region. (B) The positions of 3 methylatable CG pairs, a transcription start site, and a polymorphic base change are depicted. (C) A single polymorphic change was identified with the indicated allele frequencies. (D) The BubR1 promoter sequences $(-395$ to +195$)$ containing wild-type $(A / A)$ or mutant homozygous $(G / G)$ alleles were PCR amplified and fused to the luciferase gene. The resulting constructs were transiently transfected into HeLa cells, and the luciferase activity was compared between the constructs containing the A/A and $G / G$ genotypes. The relative luciferase to $\beta$-galactosidase activity was determined from three independent experiments.

genic induction of tumors, but also resulted in a higher incidence of tumors than in wild-type mice (Dai et al., 2004). Furthermore, reduction of BubR1 levels in $\mathrm{Apc}^{\mathrm{Min} /+}$ mice by generating $\mathrm{Apc}^{\mathrm{Min} /+}$ BubR $1^{+-}$mice resulted in a 10 -fold increase in the number of high grade tumors (Rao et al., 2005). 
These findings indicate that a decrease in the expression level of BubR1 protein is probably a mechanism for the chromosomal instability known to be associated with tumorigenesis. Our results indicate that significant populations of tumor cells with reduced levels of BubR1 expression exhibit restored BubR1 mRNA levels following demethylation, thereby indicating that BubR1 gene promoter hypermethylation might be a major factor in BubR1 expression.

Although impairment of the mitotic checkpoint is frequently associated with tumorigenesis, mutational inactivation of mitotic-checkpoint genes is only observed in a small proportion of human cancers (Takahashi et al., 1999; Haruki et al., 2001; Hernando et al., 2001; Jallepalli and Lengauer, 2001; Saeki et al., 2002). For instance, a few mutations in the coding sequence for BubR1 were reported to be present in human cancers (Lengauer et al., 1997; Kops et al., 2005). A recent report has linked MVA to mutations in the BubR1 gene (Hanks et al., 2004), however, it is not known whether these BubR1 mutations actually caused the chromosomal instability and aneuploidy phenotype in the cells. Transcripts of the mitotic-checkpoint genes are maintained at different levels in human cancer cells compared to their neighboring normal cells (Shichiri et al., 2002; Wang et al., 2000, 2002). These observations indicate that transcriptional failure or promoter dysfunction may be responsible for changes in the checkpoint-protein levels causing induction of mitotic-checkpoint dysfunction and chromosomal instability. We recently reported that transcriptional dysfunction of Mad2 is frequently observed in hepatocellular carcinoma cells, and that down-regulation of Mad2 protein expression is correlated with transcriptional silencing of the Mad2 promoter by hypermethylation (Jeong et al., 2004). These results indicate that a relationship between transcriptional abnormality of the mitotic- checkpoint gene and mitotic abnormality exists in human cancers.

Genes may be inactivated under both normal and pathological conditions through promoter hypermethylation, transcription factor dysfunction, and promoter mutation (Herman and Baylin, 2000; Baylin et al., 2001; Rush and Plass, 2002; Yang et al., 2003). Recent studies have demonstrated an association between human cancers and promoter hypermethylation (Lee et al., 2004; Park et al., 2005). Thus, cytosine methylation is highly mutagenic, causing a $\mathrm{C}$ to $\mathrm{T}$ mutation resulting in loss of the $\mathrm{CpG}$ methylacceptor site, and aberrant methylation of $\mathrm{CpG}$ is characteristic of many human cancers (Egger et al., 2004; Feinberg and Tycko, 2004; Adcock et al., 2006). We have demonstrated that the aberrant expression of BubR1 in cancer cells is associated with promoter hypermethylation and we have provided evidence that the methylation states of two $\mathrm{CpG}$ sites in the BubR1 promoter are integrated into the regulation mechanism of BubR1 expression. Our study provides evidence that promoter hypermethylation of the BubR1 gene may be an important regulator of BubR1 expression. It is also possible that not only promoter hypermethylation but also post-translational degradation and stoichiometric alterations of BubR1 contribute to the dysfunction of BubR1 that abrogates the mitotic-checkpoint resulting in chromosomal instability.

In conclusion, our results indicate that changes in BubR1 promoter hypermethylation patterns are a causative factor for aberrant expression of the BubR1 gene in human cancer cells, and provide insight into the molecular mechanisms that regulate BubR1 expression.

\section{Acknowledgement}

This work was supported by research grants from the Korea Research Foundation (KRF-2005-042- E00020), the Korea Health 21 R\&D Project, Ministry of Health and Welfare (03-PJ10-PG13-GD01-0002), and the Korea Science and Engineering Foundation through the Rheumatism Research Center (RII- 2002-098-05003, 2006).

\section{References}

Abrieu A, Kahana JA, Wood KW, Cleveland DW. CENP-E as an essential component of the mitotic checkpoint in vitro. Cell 2000;102:817-26

Adcock IM, Ford P, Barnes PJ, Ito K. Epigenetics and airways disease. Respir Res 2006;7:21-40

Baker DJ, Jeganathan KB, Cameron JD, Thompson M, Juneja S, Kopecka A, Kumar R, Jenkins RB, de Groen PC, Roche P, van Deursen JM. BubR1 insufficiency causes early onset of aging-associated phenotypes and infertility in mice. Nat Genet 2004;36:744-9

Baylin SB, Esteller M, Rountree MR, Bachman KE, Schuebel $\mathrm{K}$, Herman JG. Aberrant patterns of DNA methylation, chromatin formation and gene expression in cancer. Hum Mol Genet 2001;10:687-92

Bird A. DNA methylation patterns and epigenetic memory. Genes Dev 2002;16:6-21

Cahill DP, Lengauer C, Yu J, Riggins GJ, Willson JK, Markowitz SD, Kinzler KW, Vogelstein B. Mutations of mitotic checkpoint genes in human cancers. Nature 1998;392:300-3

Chan GK, Jablonski SA, Sudakin V, Hittle JC, Yen TJ. Human BUBR1 is a mitotic checkpoint kinase that monitors CENP-E functions at kinetochores and binds the cyclosome/APC. J Cell Biol 1999;146:941-54

Chang HJ, Yoo BC, Lim SB, Jeong SY, Kim WH, Park JG. Metabotropic glutamate receptor 4 expression in colorectal 
carcinoma and its prognostic significance. Clin Cancer Res 2005;11:3288-95

Chen RH, Waters JC, Salmon ED, Murray AW. Association of spindle assembly checkpoint component XMAD2 with unattached kinetochores. Science 1996;274:242-6

Dai W, Wang Q, Liu T, Swamy M, Fang Y, Xie S, Mahmood R, Yang YM, Xu M, Rao CV. Slippage of mitotic arrest and enhanced tumor development in mice with BubR1 haploinsufficiency. Cancer Res 2004;64:440-5

Egger G, Liang G, Aparicio A, Jones PA. Epigenetics in human disease and prospects for epigenetic therapy. Nature 2004;429:457-63

Feinberg AP, Tycko B. The history of cancer epigenetics. Nat Rev Cancer 2004;4:143-53

Hanks S, Coleman K, Reid S, Plaja A, Firth H, Fitzpatrick D, Kidd A, Mehes K, Nash R, Robin N, Shannon N, Tolmie J, Swansbury J, Irrthum A, Douglas J, Rahman N. Constitutional aneuploidy and cancer predisposition caused by biallelic mutations in BUB1B. Nat Genet 2004;36:1159-61

Haruki N, Saito H, Harano T, Nomoto S, Takahashi T, Osada $\mathrm{H}$, Fujii Y, Takahashi T. Molecular analysis of the mitotic checkpoint genes BUB1, BUBR1 and BUB3 in human lung cancers. Cancer Lett 2001;162:201-5

Herman JG, Baylin SB. Promoter-region hypermethylation and gene silencing in human cancer. Curr Top Microbiol Immunol 2000;249:35-54

Hernando E, Orlow I, Liberal V, Nohales G, Benezra R, Cordon-Cardo $\mathrm{C}$. Molecular analyses of the mitotic checkpoint components hsMAD2, hBUB1 and hBUB3 in human cancer. Int J Cancer 2001;95:223-7

Jallepalli PV, Lengauer C. Chromosome segregation and cancer: cutting through the mystery. Nat Rev Cancer 2001;1:109-17

Jeong SJ, Shin HJ, Kim SJ, Ha GH, Cho BI, Baek KH, Kim CM, Lee CW. Transcriptional abnormality of the hsMAD2 mitotic checkpoint gene is a potential link to hepatocellular carcinogenesis. Cancer Res 2004;64:8666-73

Kops GJ, Weaver BA, Cleveland DW. On the road to cancer: aneuploidy and the mitotic checkpoint. Nat Rev Cancer 2005;5:773-85

Lampson MA, Kapoor TM. The human mitotic checkpoint protein BubR1 regulates chromosome-spindle attachments. Nat Cell Biol 2005;7:93-8

Lee JK, Kim MJ , Hong SP and Hong SD. Inactivation patterns of $p 16 /$ INK4A in oral squamous cell carcinomas. Exp Mol Med 2004;36:165-71

Lengauer C, Kinzler KW, Vogelstein B. DNA methylation and genetic instability in colorectal cancer cells. Proc Natl Acad Sci USA 1997;94:2545-50

Mao Y, Abrieu A, Cleveland DW. Activating and silencing the mitotic checkpoint through CENP-E-dependent activation/ inactivation of BubR1. Cell 2003;114:87-98

Nasmyth K, Peters JM, Uhlmann F. Splitting the chromosome: cutting the ties that bind sister chromatids. Science 2000;

\section{8:1379-85}

Park WS, Cho YG, Kim CJ, Song JH, Lee YS, Kim SY, Nam SW, Lee SH, Yoo NJ, Lee JY. Hypermethylation of the RUNX3 gene in hepatocellular carcinoma. Exp Mol Med 2005; $37: 276-81$

Rao CV, Yang YM, Swamy MV, Liu T, Fang Y, Mahmood R, Jhanwar-Uniyal M, Dai W. Colonic tumorigenesis in BubR1+/ApcMin/+ compound mutant mice is linked to premature separation of sister chromatids and enhanced genomic instability. Proc Natl Acad Sci USA 2005;102:4365-70

Rush LJ, Plass C. Alterations of DNA methylation in hematologic malignancies. Cancer Lett 2002;185:1-12

Saeki A, Tamura S, Ito N, Kiso S, Matsuda Y, Yabuuchi I, Kawata S, Matsuzawa Y. Frequent impairment of the spindle assembly checkpoint in hepatocellular carcinoma. Cancer 2002;94:2047-54

Shichiri M, Yoshinaga K, Hisatomi H, Sugihara K, Hirata Y. Genetic and epigenetic inactivation of mitotic checkpoint genes hBUB1 and hBUBR1 and their relationship to survival. Cancer Res 2002;62:13-7

Shin HJ, Baek KH, Jeon AH, Park MT, Lee SJ, Kang CM, Lee HS, Yoo SH, Chung DH, Sung YC, McKeon F, Lee CW. Dual roles of human BubR1, a mitotic checkpoint kinase, in the monitoring of chromosomal instability. Cancer Cell 2003;4: 483-97

Sudakin V, Ganoth D, Dahan A, Heller H, Hershko J, Luca FC, Ruderman JV, Hershko A. The cyclosome, a large complex containing cyclin-selective ubiquitin ligase activity, targets cyclins for destruction at the end of mitosis. Mol Biol Cell 1995;6:185-98

Takahashi T, Haruki N, Nomoto S, Masuda A, Saji S, Osada $\mathrm{H}$, Takahashi T. Identification of frequent impairment of the mitotic checkpoint and molecular analysis of the mitotic checkpoint genes, hsMAD2 and p55CDC, in human lung cancers. Oncogene 1999;18:4295-300

Taylor SS, McKeon F. Kinetochore localization of murine Bub1 is required for normal mitotic timing and checkpoint response to spindle damage. Cell 1997;89:727-35

Taylor SS, Ha E, McKeon F. The human homologue of Bub3 is required for kinetochore localization of Bub1 and a Mad3/Bub1-related protein kinase. J Cell Biol 1998;142:1-11

Tsukasaki K, Miller CW, Greenspun E, Eshaghian S, Kawabata H, Fujimoto T, Tomonaga M, Sawyers C, Said JW, Koeffler HP. Mutations in the mitotic checkpoint gene, MAD1L1, in human cancers. Oncogene 2001;20:3301-5

Wang $X$, Jin DY, Wong YC, Cheung AL, Chun AC, Lo AK, Liu $Y$, Tsao SW. Correlation of defective mitotic checkpoint with aberrantly reduced expression of MAD2 protein in nasopharyngeal carcinoma cells. Carcinogenesis 2000;21:2293-7

Wang $\mathrm{X}$, Jin DY, Ng RW, Feng $\mathrm{H}$, Wong YC, Cheung AL, Tsao SW. Significance of MAD2 expression to mitotic checkpoint control in ovarian cancer cells. Cancer Res 2002;62:1662-8

Wang Q, Liu T, Fang Y, Xie S, Huang X, Mahmood R, Ramaswamy G, Sakamoto KM, Darzynkiewicz Z, Xu M, Dai W. BUBR1 deficiency results in abnormal megakaryopoiesis. 
Blood 2004;103:1278-85

Waters JC, Chen RH, Murray AW, Salmon ED. Localization of Mad2 to kinetochores depends on microtubule attachment, nottension. J Cell Biol 1998;141:1181-91
Yang B, Guo M, Herman JG, Clark DP. Aberrant promoter methylation profiles of tumor suppressor genes in hepatocellular carcinoma. Am J Pathol 2003;163:1101-7

$\mathrm{Yu} \mathrm{H}$. Regulation of APC-Cdc20 by the spindle checkpoint. Curr Opin Cell Biol 2002;14:706-14 